\title{
Effects of programmed initial strategies in a prisoner's dilemma game ${ }^{1}$
}

\author{
STUART OSKAMP, Claremont Graduate \\ School, Claremont, Calif. 91711
}

Five treatment conditions were compared in a typical Prisoner's Dilemma experimental situation. Four conditions involved different programmed strategies for the first 15 trials followed by 60 trials of tit-for-tat matching of the S's previous response; the fifth condition involved free play of two real Ss for 75 trials. Two identical experiments with populations varying widely in overall cooperation (54 male undergraduates and 60 high-school boys) yielded quite similar results. The free-play condition produced significantly less cooperation than all other conditions. The relatively small differences among the other conditions were probably due to the overriding effects of the tit-for-tat strategy with which they all concluded.

An important topic in studies of experimental gaming has been the effect of programmed strategies on cooperation by the Ss. Pilisuk \& Rapoport (1964) have shown that in a Prisoner's Dilemma (PD) game the levels of cooperation of the two players become very highly correlated over a long series of trials, implying that the first few moves may be quite crucial for the development of cooperation. Nevertheless, only a few investigators have studied the later effects of programmed initial strategies. Scodel (1962) found that a strategy of $100 \%$ competition which suddenly shifted to $100 \%$ cooperation produced more later cooperation than did one which was $100 \%$ cooperative from the beginning. Similarly, Harford \& Hill (1967) and Harford \& Solomon (1967) showed that a "reformed sinner" strategy (100\% competition, then $100 \%$ cooperation, then tit-for-tat matching of the S's previous response) produced more later cooperation than did a "lapsed saint" strategy (100\% cooperation, then tit-for-tat matching). The present study compared strategies similar to Scodel's and Harford's with a free-play condition and with an initial program which was empirically designed to produce maximum cooperation. METHOD

In addition to the free-play condition, where two Ss were actually paired and allowed complete freedom of response for 75 trials, there were four conditions that consisted of four different programmed strategies for the first 15 trials, followed in each case by 60 trials of tit-for-tat matching of the S's previous response. The $100 \%$ cooperative condition had $15 \mathrm{C}$ responses in a row. 2 The cooperative shift condition used a "reformed sinner" strategy $(6 \mathrm{D}, 9 \mathrm{C})$, while the competitive shift condition was somewhat similar to a "lapsed saint" strategy $(5 \mathrm{C}, 6 \mathrm{D}, 4 \mathrm{C})$. Finally, the flexible condition had more shifts and included contingent competitive responses designed to punish attempted exploitation by an $\mathrm{S}(\mathrm{D}, 2 \mathrm{C}, \mathrm{D}, 3 \mathrm{C}, 3 \mathrm{~V}$, $\left.2 C^{*}, 3 C\right)$. This strategy was constructed on the basis of results from a previous experiment which were analyzed to determine what pattern of initial moves on the first five trials was most productive of cooperation on the subsequent trials (both immediate and long range). On Trials 6-15, this strategy was cooperative unless it met with exploitation, in which case it retaliated firmly and then returned to cooperating.

The payoff matrix was a frequently used PD matrix which can be specified (using the convention established by Pilisuk \& Rapoport, 1964) by the following parameters: $\mathrm{R}=3 \phi, \mathrm{S}=0, \mathrm{~T}=5 \phi$, and $\mathrm{P}=1 \not$. The experimental setup was a typical one, with four Ss being run at one time in a situation of visual isolation and no communication. Though Ss saw each other before the experiment commenced, they did not know with whom they were paired. The instructions were tape recorded for uniformity of presentation and to avoid E bias effects. They were similar to the standard instructions used by Oskamp \& Perlman (1965) but were elaborated with additional description and examples in order to insure their comprehension by high school Ss. Following the instructions, Ss were given four practice trials illustrating the four possible outcomes of a trial. The equipment was not automated, and $E$ manually recorded each S's response on each trial. Instead of seeing feedback lights, the Ss received feedback on the outcome of each trial through an opening in their surrounding partition where $\mathrm{E}$ either silently placed a poker chip labeled $5 \not \notin, 3 \not$, or $1 \not \subset$, or gave them no poker chip. At the end of the session, the poker chips were exchanged for cash, as promised in the instructions. After each trial Ss recorded their own response, the other person's response, and their own earnings; at the end of the session, they filled out a brief questionnaire.

The procedures described above were used in two identical experiments with differing populations. The first experiment used 54 undergraduates, at a small, liberal arts men's college, who were expected to serve in the study as part of their introductory psychology course requirements. They were very atypical in their high level of cooperation (mean $=78 \%$ on Trials 16.75), so the second experiment was run with a group of 60 high school boys who were volunteers from a drivereducation class. They produced a more typical level of cooperation $($ mean $=45 \%)$. The four Ss in each experimental session were randomly assigned to one of the five treatment conditions. In all conditions except the free-play condition, if one of the Ss failed to appear at the appointed time, a confederate was used to maintain the appearance of two pairs of Ss, but his responses were not included in the data.

\section{RESULTS}

The most dramatic finding of the study was the great difference in cooperation between the two populations. These results are consistent with those of previous studies with the same populations (Oskamp \& Kleinke, 1968; Oskamp \& Perlman, 1965 ), the latter of which investigated some of the reasons for the atypically high cooperation found with these small-college students.

The mean levels of cooperation for the five treatment conditions over blocks of trials are shown in Fig. 1 for the first experiment and in Fig. 2 for the second experiment. The data are plotted separately for the posttreatment trials (16-75) and for the initial trials (including Trials $16-20$, since it took the Ss a few trials to realize that the programs of the first 15 trials had changed and to respond to that change). Though the graphs contain that slight degree of overlapping data, there is no overlap of data in the following statistical tests, which were computed separately for Trials 1-15 and 16-75.

The two figures indicate marked similarities in the results of the two experiments as well as some differences. In both studies there was a significant rising linear trend in cooperation over Trials 16-75. In both studies the five treatment conditions finished in the same rank order of cooperation on the last 10 trials (100\% cooperation highest, then cooperative shift, flexible, competitive shift, and free-play lowest). In both experiments the flexible condition produced the highest early cooperation on Trials $16-45$ but then lost out to the $100 \%$ cooperative and cooperative-shift conditions on Trials 46-75. Most strikingly, in both studies the free-play condition produced by far the lowest level of cooperation, while the other four 


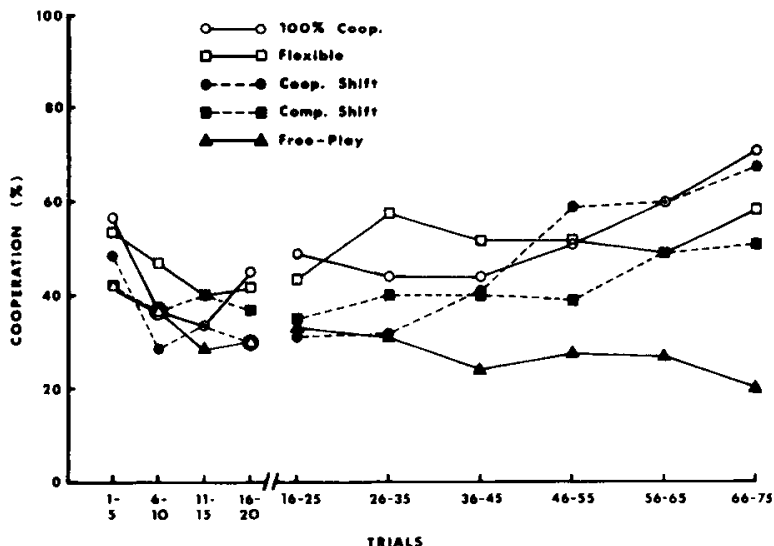

Fig. 1. Mean cooperation levels for five treatment conditions in Experiment 1.

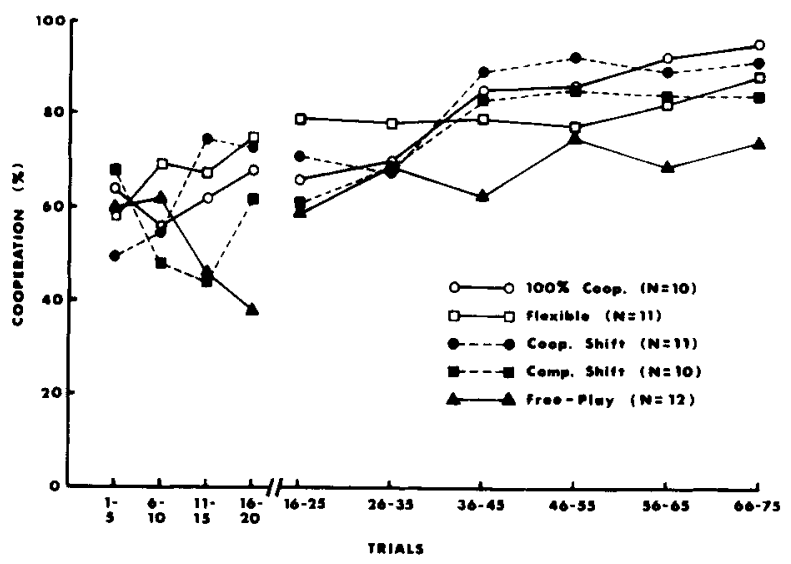

Fig. 2. Mean cooperation levels for five treatment conditions in Experment 2 (each group $N=12$ ). conditions were relatively similar in their resulting cooperation levels.

Significance tests on the data from Experiment 1 showed that for Trials 1-15 only the Treatment by Trials interaction was significant $(F=3.48, \mathrm{df}=8 / 98$, $\mathrm{p}=.01$ ), and for Trials $16-75$ only the trials main effect was significant $(F=10.61, \mathrm{df}=5 / 245, \mathrm{p}=.001)$. In Experiment 2, for Trials 1-15, only the trials main effect was significant $(F=8.53$, $\mathrm{df}=2 / 110, p=.001$ ), and for Trials 16.75 all three effects were significant (treatment $\mathrm{F}=2.64, \mathrm{df}=4 / 55, \mathrm{p}=.05 ;$ trials $\mathrm{F}=6.72, \mathrm{df}=5 / 275, \mathrm{p}=.001 ;$ Treatment by Trials interaction $F=2.72, \mathrm{df}=20 / 275$, $\mathrm{p}=.001$ ).

Despite the differences in significant effects between the two experiments, their main findings concerning the results of the five treatment conditions on Trials 16-75 were remarkably similar. In both experiments, Duncan's multiple-range tests showed that the free-play condition was significantly below all four other conditions and that the other four conditions were very closely grouped together. In Experiment 1 the means were: cooperative shift, $83 \% ; 100 \%$ cooperation, 82\%; flexible, $81 \%$; competitive shift, $78 \%$; and free-play, $68 \%$. In Experiment 2 the corresponding figures were $48 \%, 53 \%, 52 \%$, $42 \%$, and $27 \%$. (Only two other significant differences were present: In Experiment 2 the competitive-shift condition was significantly below the $100 \%$ cooperative and flexible conditions.)

\section{DISCUSSION}

There were two major findings of these studies: (1) the lower cooperation produced by the free-play condition than by all other conditions, and (2) the apparent relative equivalence of the other four conditions in producing cooperation. The first of these findings suggests that Ss in a free-play situation display greater response variability than do most programmed strategies, and, as a consequence, they tend to drift toward higher levels of competition, often culminating in joint competitive "lock-ins." The second major finding does not completely demonstrate that the four programmed strategies are equivalent in their effects; rather, it was probably due to the overriding effects of the 60 trials of tit-for-tat matching with which they all concluded. This interpretation is supported by the fact that in both experiments the differences between the four strategies at the beginning of the tit-for-tat matching (Trials 16.35) were greater than at its end (Trials 56-75). Similarly, in the Harford \& Solomon (1967) study, the converging curves of the two initial strategies after about 20 trials of tit-for-tat matching add further support to the interpretation.

\section{REFERENCES}

HARFORD, T. C., \& HILL, M. Variations in behavioral strategies and interpersonal trust in a two-person game with male alcoholics Journal of Clinical Psychology, 1967, 23, 33-35.

HARFORD, T., \& SOLOMON, L. "Reformed sinner" and "lapsed saint" strategies in the Prisoner's Dilemma game. Journal of Conflict Resolution, 1967, 11, 104-109.

OSKAMP, S., \& PERLMAN, D. Factors affecting cooperation in a Prisoner's Dilemma game. Journal of Conflict Resolution, 1965, 9 , 359-374.

OSKAMP, S., \& KLEINKE, C. Amount of reward as a variable in the Prisoner's Dilemma game. Paper presented at the California State Psychological Association meeting in Santa Barbara, January 1968.

PILISUK, M., \& RAPOPORT, A. A non-zero-sum game model of some disarmanent problems. Peace Research Society (International) Papers, $1964,1,57-78$

SCODEL, A. Induced collaboration in some non-zero-sum games. Joumal of Conflict Resolution, 1962, 6, 335-340.

\section{NOTES}

1. Paper presented at the Western Psychological Association meeting in San Diego, March 1968. Support for the study was provided by U.S. Public Health Service Research Grant MH 11505-01 and by a research grant from Claremont Graduate School. Thanks are extended to Kenneth Nacovanni for his assistance and to administrative personnel of the Claremont Unified School District for their cooperation.

2. The following symbols are used throughout this paper: $C$ for cooperative, $D$ for defecting (i.e., competitive), $\mathrm{V}$ for a variable response (C unless $S$ gave two Ds on the previous trials, in which case the program retaliated with three Ds in a row), $C^{*}$ for a conditional cooperative response (C unless the program was completing the three Ds resulting from a $V$ response). 